\title{
Physical Nanoindentation: From Penetration Resistance to Phase-Transition Energies
}

\author{
Gerd Kaupp \\ University of Oldenburg, Oldenburg, Germany \\ Email: gerd.kaupp@uni-oldenburg.de
}

How to cite this paper: Kaupp, G. (2019) Physical Nanoindentation: From Penetration Resistance to Phase-Transition Energies. Advances in Materials Physics and Chemistry, 9, 103-122.

https://doi.org/10.4236/ampc.2019.96009

Received: June 4, 2019

Accepted: June 25, 2019

Published: June 28, 2019

Copyright ( 2019 by author(s) and Scientific Research Publishing Inc. This work is licensed under the Creative Commons Attribution International License (CC BY 4.0).

http://creativecommons.org/licenses/by/4.0/

(c) (i) Open Access

\begin{abstract}
The ISO standard 14577 is challenged for its violation of the energy law, its wrong relation of normal force $F_{\mathrm{N}}$ with impression depth $h$, and for its iterative treatments. The solution of this dilemma is the use of sacrosanct simplest calculation rules for the loading parabola (now $F_{\mathrm{N}}=k h^{3 / 2}$ ) giving straight lines for cones, pyramids and wedges. They provide the physical penetration resistance hardness $k$ with dimension $\left[\mathrm{Nm}^{-3 / 2}\right]$ and allow for non-iterative calculations with closed formulas, using simple undeniable calculation rules. The physically correct $F_{\mathrm{N}}$ versus $h^{3 / 2}$ plot is universally valid. It separates out the most common surface effects and reveals gradients. It provides unmatched precision, including reliability checks of experimental data. Regression analysis of $F_{\mathrm{N}}$ versus $h^{3 / 2}$ plots reveals eventual unsteadiness kink phase-transition onset with the transition-energy. This is shown for all kinds of solid materials, including salts, silicon, organics, polymers, composites, and superalloys. Exothermic and endothermic single and consecutive multiple phase-transitions with their surface dependence are distinguished and the results compared in 5 Tables. The sharp phase-transition onsets and the transition energies provide unprecedented most important materials' characteristics that are indispensable for safety reasons. ISO ASTM is thus urged to thoroughly revise ISO 14577 and to work out new standards for the mechanically (also thermally) stressed materials. For example, the constancy of the first phase-transition parameters must be controlled, and materials must only be admitted for maximal forces well below the first phase-transition onset. Such onset loads can now be easily calculated. The nevertheless repeated oppositions against the physical analysis of indentations rest on incredibly poor knowledge of basic mathematics, errors that are uncovered. The safety aspects caused by the present unphysical materials' parameters are discussed.
\end{abstract}

\section{Keywords}

Energy Law Violation, ISO-14577 Challenge, Calculation Rules for 
Indentations, Phase-Transition Onset and Energy, Multiple Transitions, Safety Problems

\section{Introduction}

We continue with our efforts since the early 2000 nds to convince ISO (International Standardization Organization) and the American branch ASTM (American Society for Testing Materials) to properly correct their ISO 14577 standard. This standard enforces the analysis of (nano) indentation curves to the whole materials sciences. However, conical or pyramidal indentation does not penetrate against a projected or iterated contact area with violation against the first energy law, which contradicts experiment. The diamond indentation rather creates the semi-angle dependent volume of the cone or the pyramid that is geometrically well known and available from all indentation compendia. A pyramid volume can also be calculated like a cone with its "effective cone angle", as repeatedly used in indentation compendia. Therefore, the mathematic calculation is indeed possible for the loading parabola that relates the force with the depth $^{3 / 2}$. The physically and mathematically founded deduction of the parabola exponent $3 / 2$ with the linear $F_{\mathrm{N}}-h^{3 / 2}$ plot is thus universally proved. It needs only the use of basic calculation rules that are sacrosanct to everybody. Any deviations from the exponent $3 / 2$ of the loading parabola are thus experimental errors. Materials with gradients are no exceptions. They still require exponent $3 / 2$ on $h$ : tangents to the loading $F_{\mathrm{N}}-h^{3 / 2}$ plot (instead of straight lines in that case) provide the physical hardness ( $k$-values) depth-dependent, which will also be valuable in these cases, as discussed in [1] for an ion implantation. The calculation rules are taught in public and private schools and cannot be argued against. Universal facts ensue throughout. Scientists, teachers, anonymous reviewers, editors, technicians, Certification Agencies, etc. must urgently stop with their believing in their errors of [2] [3] [4] and of ISO 14577. Their basic errors are the false exponent 2 on $h$ and their violation of the first energy law. ISO etc. are still continuously exacting worldwide agreement. Actually, they think that the undisputed elastic and plastic deformations upon indentation can be created from nothing since 1939! Clearly, as the force-depth loading parabolas do not proceed with $h^{2}$, as erroneously proposed since 1939 by Love [2], 1965 Sneddon [3], 1992 Oliver-Pharr [4], ISO 14577, etc., their ISO-hardnesses and ISO moduli are multiply iterated but not calculated. Conversely, diverging empirical results were finally published since 2004 [5] and 2005 [6] after various preceding international lectures. The mathematically proved exponent $3 / 2$ on $h$ (Equation (1)) [7] that experimentally correlates excellently $\left(\mathrm{R}^{2}>0.999-0.9999\right)$ had the advantage to physicochemical correctly identify and remove the various surface effects (including tip rounding). Importantly, it also detected phase-transitions with their onset data. But strange resistance arose against the iteration-less calculations. And surprisingly, this did not change after the break-through, when 
elementary calculation rules quantified the universal fraction of applied energy that is responsible for the elastic plus plastic deformations with mathematical precision. We apply $20 \%$ of the applied work and use the proved exponent $3 / 2$ on $h$. But $33.33 \%$ violation is still tolerated by using the false exponent 2 . Only the proved calculation settles the violation of the energy law with the factor 0.8 (Equation (4)), but it is strictly connected to the exponent $3 / 2$. This could again only be published after a large delay in 2013 [8]. It allows now a distinction between the applied work (by the instrument) and indentation work (the work for the vertical impression) when using the proved correct exponent (Equation (4)). The final universality of the exponent $3 / 2$ was mathematically proved with the most important, particularly elegant and straightforward one-page physical deduction [7]. It used only simple mathematical equations but could only appear with delay in 2016 [7]. These calculations proved the validity of the earlier amply verified empiric results and opened unprecedented new horizons with the first physical hardness that is the penetration resistance $k$ [1]. Unfortunately, the undeniable calculation rules are still not widely appreciated, and the necessary standardization is certainly difficult for ISO ASTM for various non-scientific reasons, not to forget the liability.

The author's very successful non-iterative plots $\left(F_{\mathrm{N}}\right.$ against $h^{3 / 2}$, Equation (1)) were unduly scolded as "Kaupp-fitting" [9] and must therefore now be called "Kaupp-plot" for not being mixed up with any "fittings", and as nobody else used it before. Such physical and precise plotting of the regression lines (correlations of always $>0.999-0.9999$ ) of hundreds of materials after the competent elimination of initial surface effects detected numerous phase-transitions by kink discontinuities separating two linear branches with different penetration resistance slopes $k_{1}$ and $k_{2}\left(\mathrm{mN} / \mu \mathrm{m}^{3 / 2}\right)$ (physical hardness). This culminated in the determination of the first phase-transition energies [8] and, temperature dependent, phase-transition activation energies [10].

As the still exacting of false exponent 2 on $h$ by ISO 14577 cannot reproduce experimental loading parabolas, people tried with "excuses" by exponent fittings, polynomial and least squares iterations. Hardness was defined as $F_{\mathrm{N}}$ over projected or iterated areas because the false exponent 2 on $h$ was not removed [4] [9]. Unbelievably, authors, anonymous reviewers, editors, ISO-ASTM, and Certification Agencies did not even try to think about getting out of their mess with their unbelievable violation against the energy law. The present author was therefore forced to point it out in a more drastically way [11]. The exponent 2 was also defended by the prescription to start the analysis of loading curves only above a "minimal force value of $30 \mathrm{mN}$ load for all solids" [12]. That means, the nano-part of the indentation by analysis of the "power function" should not be considered at all in nanoindentations. Or it has been claimed and imaged with very short log-log plots (their Figure 4 in [13]) that the exponent 2 on $h$ would be "validated" at high $F_{\mathrm{N}}$ values. Such argumentation shows however little expertise in basic mathematics: all parabolas $F_{\mathrm{N}}=k h^{\mathrm{n}}$ loose more and more of their flexure at increasing $F_{\mathrm{N}}$ for all exponents n. However the $k$ values of parabolas 
depend strongly on the exponent $\mathrm{n}$ and even worse, $k$ is not a dimensionless constant, but its dimension is $\left[\mathrm{N} / \mathrm{m}^{\mathrm{n}}\right]$. The requirement of equal dimension on both sides of every equation has been poorly disregarded. The same mathematical error is made with exponent fitting: for example [14] fits loading curves from zero (not removing the initial surface effect) to various indentation depths. He obtains thus very diverse broken exponents (e.g. $\mathrm{n}=1.64533$, or 1.75265 , or 1.82723 , etc. with respective " $k$-values" of $0.61897,0.41377$, and $3.0003 \times 10^{-4}$, but without dimensions. Why did the anonymous referees and editors of that paper not stop the print of such nonsense? The same paper [14] tried to disprove the Kaupp-plot by totally falsely claiming that "Kaupp" would draw a line through three initial points of his initial surface effect (at a tip-rounding of 300 $\mathrm{nm}$ !) and cut it with the second linear branch extension in his imaged Kaupp-plot. But the cited "Kaupp" always eliminated and eliminates initial surface effects from regressions and he only considers the kink between the also in [14] clearly present first and second linear branches! Another unfair attack against the Kaupp-plot was by the above mentioned [9], senior author Durst: these authors claim that the Oliver-Pharr [4] and ISO 14577 definition of indentation hardness as force over area would "theoretically confirm" the exponent 2 on $h$ and thus disprove the Kaupp-plot. How can a definition of an iterated (with a total of 11 free parameters in two steps) "hardness" be the basis of a physical deduction? This is more of a juggler trick but not reasonable or scientific. Again, why did anonymous reviewers and editors not reject such publication? Also, finite element calculations cannot "confirm" the exponent 2 on $h$ because they converge to $h^{2}$, which of course cannot prove anything. Also, any claim that such FE-calculations would reproduce experimental results are incorrect, even if such claim was made with curves on different pages in the same publication (e.g. in [15]). Such a claim was easily disproved by curve analyses in [1].

Despite such, unfortunately, continuing fights against the iteration-free mathematical treatment on the clear-cut physical foundation and mathematical proof [7] with closed formulas, the correct analyses opened unprecedented new horizons to the indentation technique. One cannot longer exact to the whole world a violation of the energy law; and one cannot deny the mathematical quantification of the indentation energy that is universally responsible for the work of elastic pressure plus all different pressure-following plastic events [8]. At the same time one must universally remove the falsifying exponent 2 on $h$ and use the proved $h^{3 / 2}$ for the loading parabola [7]. There is now for the first time a physically founded indentation hardness that is the penetration resistance $k$ with dimension $\left[\mathrm{N} / \mathrm{m}^{3 / 2}\right]$. It is simply obtained as the slope of the first regression line (Equation (1) or Equation (2)) always with correlation coefficient $>0.999-0.9999$ ) of the Kaupp-plot before the first phase-transition onset. It provides also for the first time the checking of the experimental correctness of previous calibrating measurements [16]. We provide the easiest and fastest means for detecting hitherto unknown phase-transition onsets of materials and for the calculation of phase-transition energies. These are unprecedented and the subject of this paper. 
Phase-transition energies have also been calculated at different temperatures, which allows for the calculation of the activation energies of the phase-transitions [10]. All of that is obtained with closed formulas, never using iterations or fittings. Materials can now be qualified for their application limits with respect to mechanical and thermal stress, for avoiding catastrophic failures in practical use. Examples are materials for various turbine materials in airliners, cars, ships, mills, bridges, buildings, roads, etc, etc. Clearly, the sudden first type transformations form polymorph interfaces. These increase the probability for the nucleation of catastrophic failures [17] [18] [19]. Their failures are generally termed as "material's fatigue". But e.g. the mosaic structures of multi-component superalloys often changes upon continued stress and stress-relief. The required constancy of the advanced mechanical parameters can and must now urgently be tested at proper time intervals by indentations with their physical analyses. We provide these in this paper from reliable data of salts, silicon, organics, polymers, composites, and superalloys. The results are compared in Tables 1-5, including face dependencies and multiple phase transitions. They are also discussed with respect to checking a posteriori the reasons for recent catastrophic failures to help to avoid them a priori for the future. Indentations of the materials are the technique of choice, but only on the basis of the calculation rules that disprove the unfortunately still common ISO-ASTM standards 14577.

\section{Materials and Methods}

The own measurements were performed with a fully calibrated Hysitron Inc. Triboscope $^{(\mathrm{R})}$ Nanomechanical Test Instrument with 2D transducer and levelling device, connected to a Nanoscope AFM, using all of about 15,000 data pairs. The apex radii of the cube corner $(55 \mathrm{~nm})$ and Berkovich $(110 \mathrm{~nm})$ diamond indenter were directly measured by AFM in tapping mode. The levelling to $\pm 1^{\circ}$ was in $x$ and $y$ direction. Loading times were $30 \mathrm{~s}$ up to $10 \mathrm{mN}$ load. Most initial data are from digitized published loading curves (Plot Digitizer 2.5.1 program; https://www.softpedia.com/) up to the microindentation regions with about 500 points. It was necessary for avoiding any bias suspicion that had sometimes been expressed by anonymous Reviewers. Fittings or iterations whatsoever were never performed. The crystal structure models were calculated using the Schakal 97 program [20]. The polished strontium titanate samples (100), (110), and (111) were from Aldrich Chemical Company. Grade 80 isotactic polypropylene was from Imam Khomeini Petroleum Co, Tehran, Iran.

The own or digitized data pairs of $F_{\mathrm{N}}$ and $h$ were read into Excel $^{(\mathrm{R})}$ for the calculation and print of the Kaupp-plot and calculation of the regressions up to and from the at first roughly judged kink position after the cut-off of the initial surface effect points. This is exemplified in Figure 1 for aragonite, purposely with a larger initial effect than usual. In that case, the surface effect is primarily due to hydrated surface twins. The precise kink position is then calculated by equating $\mathrm{y}_{1}$ and $\mathrm{y}_{2}$ that contain the slopes $k$ and axis-cuts $F_{\mathrm{a}}$ (Equation (2)). The y denotes 
$F_{\mathrm{N}}$ and the $\mathrm{x}$ denote $h^{3 / 2}$, while the regression certainties are calculated as $\mathrm{R}^{2}$. All transition energy values are normalized per force unit for the respective polymorph ranges.

We repeat here the evaluation formulas from [16] for convenience. These contain all necessary correction requirements that might be necessary and are self-evident based on the physically deduced Equation (1) [7]. The factor 0.8 in Equation (4) settles the energy law violation [8], but only for the correct exponent $3 / 2$ on $h$ (Equation (1)). The calculations of the phase-transition work were performed with 10 figures to avoid rounding errors. The tabulated values were then reasonably rounded. Equation (2) is used for interconversions between different units of the $k$-values (physical hardness) and for the values at the kink points or end points. This has been exemplified with the data in Figure 1 that were converted into the units of Table 1.

$$
\begin{gathered}
F_{\mathrm{N}}=k h^{3 / 2} . \\
F_{\mathrm{N}}=k h^{3 / 2}+F_{1-\mathrm{a}} \cdot \\
W_{\text {1-applied }}=0.5 h_{\text {kink }}\left(F_{\mathrm{N} \text {-kink }}+F_{1-\mathrm{a}} h_{\text {kink }}\right) . \\
W_{1 \text {-indent }}=0.8 W_{1 \text {-applied }} \cdot \\
W_{\text {2-indent }}=0.4 k\left(h^{5 / 2}-h_{\text {kink }} 5 / 2\right)+F_{2-\mathrm{a}}\left(h-h_{\text {kink }}\right) . \\
\text { full } W_{\text {applied }}=0.5 F_{\mathrm{N} \text {-max }} h_{\text {max }} . \\
W_{\text {transition }}=\text { full } W_{\text {applied }}-\sum\left(W_{\text {applied }}\right) .
\end{gathered}
$$

The slopes of the different linear branches (Figure 1) are the $k$-values (depth independent penetration resistance $=$ physical hardness $)$ with dimension $\left[\mathrm{N} / \mathrm{m}^{3 / 2}\right]$ (but not $\mathrm{N} / \mathrm{m}^{2}$ ). They are obtained together with the axis cuts $\left(F_{\mathrm{a}}\right)$. The initial

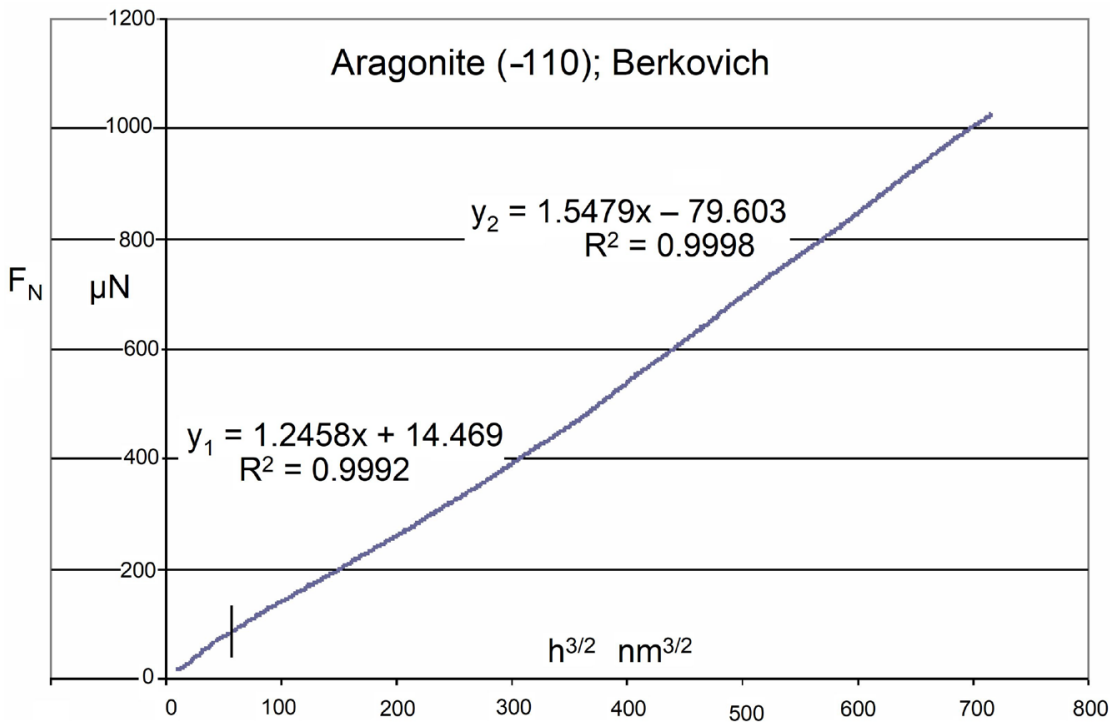

Figure 1. Kaupp-plot $\left(F_{\mathrm{N}}\right.$ versus $\left.h^{3 / 2}\right)$ analysis, as exemplified with a Berkovich indentation onto aragonite $\left(\mathrm{CaCO}_{3}\right.$; Table 1$)$, showing the phase-transition kink unsteadiness onset by the kink and cut-off of the initial surface effects that include the tip rounding. 
Table 1. Penetration resistance and phase-transition energies of various types of materials (Berkovich), including organics (cube corner).

\begin{tabular}{|c|c|c|c|c|c|c|}
\hline Material & $k_{1}$ and $k_{2}\left(\mathrm{mN} \mu \mathrm{m}^{3 / 2}\right)$ & $\begin{array}{l}F_{\mathrm{Nmax}} \\
(\mathrm{mN})\end{array}$ & $\begin{array}{l}F_{\text {Nkink }} \\
(\mathrm{mN})\end{array}$ & $\begin{array}{l}h_{\text {kink }} \\
(\mu \mathrm{m})\end{array}$ & $\begin{array}{l}W_{\text {transition }} / \mathrm{mN} \\
(\mathrm{mN} \mu \mathrm{m} / \mathrm{mN})\end{array}$ & Literature for Data Origin \\
\hline Aragonite $\mathrm{CaCO}_{3}(-110)$ & $\begin{array}{l}39.396 \\
48.962\end{array}$ & 1.0 & 0.4086 & 0.04644 & 0.002758 & $\begin{array}{c}\text { Kearney, Phys Rev Lett 2006, } \\
\text { 96, } 255505\end{array}$ \\
\hline Calcite $\mathrm{CaCO}_{3}(100)^{\mathrm{a})}$ & $\begin{array}{l}17.911 \\
23.176\end{array}$ & 10.0 & 0.3655 & 0.08266 & 0.01599 & $\begin{array}{c}\text { Guillonneau, J Mater Res 2012, } \\
\text { 22, } 2551\end{array}$ \\
\hline Calcite $\mathrm{CaCO}_{3}(100)^{\mathrm{b})}$ & $\begin{array}{l}33.156 \\
48.943\end{array}$ & $40.0^{\mathrm{b})}$ & 11.869 & 0.4940 & 0.10692 & $\begin{array}{l}\text { Presser, J Mater Sci 2010, 45, } \\
2408\end{array}$ \\
\hline Sapphire $\mathrm{Al}_{2} \mathrm{O}_{3}$ & $\begin{array}{l}236.05 \\
267.08\end{array}$ & 90.0 & 34.326 & 0.2763 & 0.13453 & Page, J Mater Res 19927450 \\
\hline Zirconium dioxide $\mathrm{ZrO}_{2}$ & $\begin{array}{l}134.74 \\
210.88\end{array}$ & 33.0 & 8.7514 & 0.1665 & 0.02828 & Zeng, Acta Mater 2001, 49, 3539 \\
\hline Tungsten W & $\begin{array}{c}95.57 \\
114.50\end{array}$ & 85.0 & 35.607 & 0.5525 & 0.070059 & $\begin{array}{c}\text { Oliver-Pharr, J Mater Res 1992, } \\
\text { 7, } 1584\end{array}$ \\
\hline $\mathrm{InGaAs}_{2}(001)$ & $\begin{array}{l}36.272 \\
32.477\end{array}$ & 2.7 & 1.2703 & 0.1070 & -0.005380 & Kaupp, Scanning 2013, 35, 392 \\
\hline $\begin{array}{c}\text { Mica, Muscovite } \\
\left.\mathrm{KAl}_{2}\left[(\mathrm{OH}, \mathrm{F})_{2} / \mathrm{AlSi}_{3} \mathrm{O}_{10}\right)\right]\end{array}$ & $\begin{array}{c}34.522 \\
3.566\end{array}$ & 50.0 & 11.556 & 0.4434 & 0.01016 & $\begin{array}{l}\text { Hutchinson, Acta Metall Mater } \\
\qquad 40295,1992\end{array}$ \\
\hline $\mathrm{Ce}\left(\mathrm{C}_{2} \mathrm{O}_{4}\right)_{2}\left(\mathrm{CO}_{2} \mathrm{H}\right)(001)$ "MOF" & $\begin{array}{l}52.848 \\
64.907\end{array}$ & 20.0 & 8.0745 & 0.3102 & 0.06554 & $\begin{array}{c}\text { Tan, J Am Chem Soc 2009, 131, } \\
14252\end{array}$ \\
\hline Pine latewood radial & $\begin{array}{l}0.1342 \\
0.1705\end{array}$ & 1.8 & 0.5469 & 2.5625 & 0.23926 & $\begin{array}{l}\text { Brandt, Acta Biomater 2000, 6, } \\
4345\end{array}$ \\
\hline Pine latewood axial & $\begin{array}{l}0.2098 \\
0.3043\end{array}$ & 3.0 & 0.9631 & 2.7638 & 0.36510 & ditto \\
\hline Saccharin $(011)^{c)}$ & $\begin{array}{l}1.9543 \\
2.3179\end{array}$ & 6.0 & 1.7108 & 0.9426 & 0.08293 & $\begin{array}{c}\text { Kira, Cryst Growth Design } \\
2010,10,4650\end{array}$ \\
\hline Benzylidene-butyrolactone $(010)^{c)}$ & $\begin{array}{l}0.4807 \\
0.5724\end{array}$ & 2.1 & 1.0634 & 1.6671 & 0.07893 & $\begin{array}{c}\text { Kaupp, Angew Chem 1996, 35, } \\
2774\end{array}$ \\
\hline
\end{tabular}

${ }^{\text {a) }}$ After initial twinning; ${ }^{\text {b) }}$ second transition of calcite; ${ }^{c}$ cube corner indenter; the organic structures are in Figure 2.<smiles>O=C1NS(=O)(=O)c2ccccc21</smiles>

Figure 2. Molecular structures of saccharin and benzylidene butyrolactone.

surface effect (water layer, surface treatments, roughness, possible zero-error, tip rounding, etc) has to be carefully separated from the desired bulk properties. Its detailed elucidation requires separate indentation but at much lower depths (here up to $100 \mu \mathrm{N}$ load). Most metals and semiconductors have hydrated oxide/hydroxide (rarely nitride) layers, often despite surface hardening by polishing. All of these contribute to $F_{\mathrm{a}}$ and have to be corrected for (Equation (2), Equation (3) and Equation (5)), but their varying values are not bulk materials constants and are thus not tabulated. 


\section{Results and Discussion}

\subsection{Various Types of Materials}

Phase-transitions upon indentations cover all types of materials and the penetration resistances $=$ physical hardnesses) of the two branches in their Kaupp-plots (they profit from the physical and mathematical proved Equations (1)-(7). Typical examples are collected in Table 1. All units are made equal by using Equation (2) with the corresponding units. It contains salts, oxides, metal, semiconductor, metal organic framework (MOF), polymer composite (wood), organic crystals, and the complicated mineral Mica. They cover nano- and micro-indentations, using Berkovich or for the organics cube corner indenters. The maximal forces are given to indicate the experimentally studied ranges. This does not exclude further phase-transitions at higher loads as has been shown with $\mathrm{NaCl}$, where 4 phase-transitions (6 polymorphs) had been located [17]. Further polymorphs are even likely for calcite, where already two phase-transitions (4 polymorphs) are energetically analyzed in Table 1 (further examples are in Tables 3-5). The $k$-, $F_{\mathrm{N}^{-}}$and $h_{\text {kink }}$-values do not systematically relate to their unprecedented transition-works that are normalized per $\mathrm{mN}$ of their ranges. We did not transform the $\mathrm{mN} \mu \mathrm{m}$ or $\mu \mathrm{Nnm}$ units into Joules for easier transformation possibility into different units. These quantities relate to the chemistry of the materials and the transitions can be mostly endothermic but also exothermic. It is seen that the less stable aragonite has a lower endothermic $W_{\text {transition }}$ than the calcite polymorph. The second transition of calcite affords about 7 times more energy than its first one. Surprisingly, the $W_{\text {transition }}$ of the very hard sapphire is only 8.4 times higher (at 94 times higher transition onset) than the first one of calcite. Furthermore, $W_{\text {transition }}$ of sapphire is only 1.6 and1.7 times higher than the ones of the organic crystals in this Table 1 . The latter are however extended molecules requiring energy consuming solid-state migrations into other polymorph structures, whereas the cooperative transformation of $\mathrm{Al}_{2} \mathrm{O}_{3}$ from its trigonal space group (R-3c) does not require considerable molecular migrations. The proportion of transition energies between $\mathrm{Al}_{2} \mathrm{O}_{3}$ (m.p. $2050^{\circ} \mathrm{C}$ ) and $\mathrm{ZrO}_{2}$ (m.p. $2715^{\circ} \mathrm{C}$ ) (4.75 fold) is much higher than the one of physical hardnesses $k$ ( 1.25 fold). This underlines the independence of transition energies from such qualities as hardness, or melting point, etc. The high pressure polymorphs of sapphire are probably either the orthorhombic $(\mathrm{Pbcn})$ or the $(\mathrm{Pbnm})$ polymorph of $\mathrm{Al}_{2} \mathrm{O}_{3}$, both with a volume decrease of $3.1 \%$ [21], even now at room temperature, because of the shearing upon pyramidal indentation. Similarly, monoclinic $\mathrm{ZrO}_{2}\left(\mathrm{P}_{1} / \mathrm{c}\right)$ transforms probably into the denser monoclinic polymorph (still $\mathrm{P}_{1} / \mathrm{c}$ ) or the orthorhombic polymorph with $(\mathrm{Pbcm})$ structure, both with higher density. The hard metal tungsten (m.p. $3400^{\circ} \mathrm{C}$ ) has a lower hardness than the two oxides, but its transition energy is 2.5 times higher than the one of $\mathrm{ZrO}_{2}$, which is quite remarkable.

Surprisingly, the semiconductor InGaAs $s_{2}$ exhibits a significantly exothermic phase-transition, and mica (Muscovite) has a very low normalized endothermic 
transition energy, smaller than the two organics. Both of them experience very easy phase-transitions and they can only be detected by our iterative-free precise technique.

The metallorganic MOF, wood, and organics exhibit phase-transition energies that are not very different from the ones of the inorganics. The anisotropy of radial or circular pinewood is remarkable. Clearly, the non-iterative technique is very sensitive and avoids all of the strange recent techniques that are wiping out all of the important information from phase-transitions with incredible data treatments.

\subsection{Bond-Breaking of Polymers}

The phase-transitions of organic polymers under mechanical load are initial bond-breakings into radicals. This requires relatively high energy if these primary cleavage products are not stabilized by substituents. Therefore, their phase-transition onset must relate to the bond energies of the weakest chain bond. Further reactions of the so formed radical pairs are manifold, but overall there is hardening by cross-linking, which is well known for the technical treatments of polymers, e.g. upon extrusions, etc. Table 2 collects the data of some linear polymers upon Berkovich indentation. Most of these are highly amorphous and their hardnesses ( $k$-values) are low. An exception is isotactic polypropylene it-PP with high crystallinity and much higher $k$-values. This is however not so important for the $\mathrm{C}-\mathrm{C}$ bond strength. It is nicely seen in Table 2 that the phase change onset (chain breaking) relates to the strength of the carbon-carbon bonds. In the case of high density polyethylene (hd-PE) without chain substitution and isotactic polypropylene (it-PP) with slightly less efficient methyl-substituents, the strong unsubstituted C-C bonds exhibit similar bond energies and thus also similar phase-transition energies, much higher than those in Table 1 . The details with kink forces and depths depend only slightly on further properties of the materials. Substitution of the polymer chains with phenyl groups as in polystyrene

Table 2. Phase-transition onsets and energies of linear polymers upon indentation.

\begin{tabular}{|c|c|c|c|c|c|c|c|}
\hline Polymer & $\begin{array}{l}k_{1} \text { and } k_{2} \\
\mathrm{mN} \mu \mathrm{m}^{3 / 2}\end{array}$ & $\begin{array}{l}F_{\mathrm{N}-\max } \\
(\mathrm{mN})\end{array}$ & $\begin{array}{l}F_{\mathrm{N}-k \text { ink }} \\
(\mathrm{mN})\end{array}$ & $\begin{array}{l}h_{\text {kink }} \\
(\mu \mathrm{m})\end{array}$ & $\begin{array}{l}W_{\text {transition }} / \mathrm{mN} \\
\mathrm{mN} \mu \mathrm{m} / \mathrm{mN}\end{array}$ & $\begin{array}{l}\text { Bond energy } \\
\left(\mathrm{kJ} / \mathrm{mol}^{\mathrm{a}}\right)\end{array}$ & $\begin{array}{l}\text { Literature of data } \\
\text { origin }\end{array}$ \\
\hline hd-PE & $\begin{array}{l}0.65776 \\
1.08782\end{array}$ & 1.0 & 0.3247 & 0.6299 & 3.0159 & 363.2 & This work \\
\hline it-PP & $\begin{array}{l}11.030 \\
14.001\end{array}$ & 3.0 & 1.8840 & 0.3064 & 3.1463 & 362.3 & This work \\
\hline PS--6C & $\begin{array}{l}0.02955 \\
0.04303\end{array}$ & 0.450 & 0.1243 & 2.6202 & 0.5401 & 272.8 & $\begin{array}{c}\text { CSM Webinar } \\
14.02 .2010\end{array}$ \\
\hline PMMA & $\begin{array}{l}4.0252 \\
4.9629\end{array}$ & 1.6 & 0.7758 & 0.3422 & 0.04116 & n.a. ${ }^{\text {b) }}$ & $\begin{array}{c}\text { Brisccoe, Appl Phys } \\
\text { 1998, 31, } 2315\end{array}$ \\
\hline Cast PC & $\begin{array}{l}2.6385 \\
3.3079\end{array}$ & 1.10 & 0.3779 & 0.2713 & 0.02083 & Loss of $\mathrm{CO}_{2}$ & ditto \\
\hline
\end{tabular}

a) 86 th Handbook of Chemistry and Physics, CRC Press, 2006; ${ }^{\text {b) }}$ not available, probably loss of the side group rather than chain breakage. 
(PS, $1.04 \mathrm{~g} / \mathrm{cm}^{3}$ ) decreases the bond energy, due to stabilization of the radicals, and thus also the phase-transition energy is decreased. The methylester groups in the side chain of polymethylmethacrylate PMMA $\left(1.19 \mathrm{~g} / \mathrm{cm}^{3}\right)$ are 13 times more effective with decreasing the transition energy when compared with polystyrene PS. The $h_{\text {kink }}$ of PMMA is 7.7 times lower even though the required onset force is 6.2 fold higher. But it appears that the elimination of methylformate $\left(\mathrm{HCO}_{2} \mathrm{CH}_{3}\right)$ is energetically easier than the chain breakage. Polycarbonate Macrolon $^{(\mathrm{R})}(\mathrm{PC})$ contains no C-C breakage chain. But the ArO-C(O)OAr bond ( $\mathrm{Ar}$ $=$ aryl) is cleaved, starting the energetically favorable loss of $\mathrm{CO}_{2}$. This is the largest decrease of phase-transition energy of the polymers in Table 2: 145 fold decrease of $W_{\text {transition }}$ when compared with the C-C breakage of PE. The analyses of cross-linked polymer indentations promise further interesting insights.

\subsection{Multiple Phase-Transitions}

Table 1 contains already the double phase-transition of calcite and it is well-known that several phase-transitions can occur consecutively at higher and higher loads. This has been shown with the depth-sensing macroindentation of sodium chloride up to $50 \mathrm{~N}$ loads with a Vickers indenter when 4 phase-transitions were detected. The thus experimentally detected 6 polymorphs formed their polymorph interfaces under load with the facilitated production of seeds for catastrophic breakages [17]. Further examples have been found by analyses of published macroindentations [22]. For example, sapphire has its second phase-transition at $12.8 \mathrm{~N}$ and $5.82 \mu \mathrm{m}$ depth (not included in Table 1) and soda-lime glass has the third transition at $14.0 \mathrm{~N}$ and $11.7 \mu \mathrm{m}$ depth (not included in Table 3) [1]. Importantly, phase-transitions are, of course, not achievable by technical one-point

Table 3. Multiple phase transitions of soda lime glass and silicon upon Berkovich indentation.

\begin{tabular}{|c|c|c|c|c|c|}
\hline Material & $\begin{array}{l}k \text {-value } \\
\mathrm{mN} \mu \mathrm{m}^{3 / 2}\end{array}$ & $h_{\text {kink }}(\mu \mathrm{m})$ & $F_{\mathrm{N} \text {-kink }}(\mathrm{mN})$ & $\begin{array}{c}W_{\text {transition }} \\
\mathrm{mN} \mu \mathrm{m} / \mathrm{mN}\end{array}$ & Origin of Data \\
\hline \multirow{3}{*}{$\begin{array}{l}\text { Soda Lime } \\
\text { Glass }\end{array}$} & 77.909 & 0.4925 & 23.6782 & 0.1173 & \multirow{3}{*}{$\begin{array}{l}\text { Oliver-Pharr 1992, } \\
\text { J Mater Res 7, } 1584\end{array}$} \\
\hline & 105.28 & 0.7739 & 58.9005 & 0.4744 & \\
\hline & 122.01 & $1.1173^{\mathrm{a})}$ & up to $120 \mathrm{mN}$ & $0.6228^{b)}$ & \\
\hline \multirow{2}{*}{$\begin{array}{l}\mathrm{Al} \text { (only the } \\
\text { experimental) }\end{array}$} & 9.7181 & 1.2105 & 12.1330 & 0.1418 & \multirow{2}{*}{$\begin{array}{c}\text { K. Zeng, Acta Mater 2001, } \\
49,3539\end{array}$} \\
\hline & 11.613 & $2.0997^{a)}$ & up to $32 \mathrm{mN}$ & $1.2095^{\mathrm{b})}$ & \\
\hline \multirow{2}{*}{$\begin{array}{l}\mathrm{Al} \text { (only data } \\
\text { up to } 90 \mathrm{mN} \text { ) }\end{array}$} & 12.036 & 3.1086 & 60.4343 & 0.2230 & \multirow{2}{*}{$\begin{array}{l}\text { Oliver-Pharr 1992, } \\
\text { J Mater Res 7, } 1584\end{array}$} \\
\hline & 13.377 & $3.8963^{\text {a) }}$ & up to $90 \mathrm{mN}$ & $2.4958^{\mathrm{b})}$ & \\
\hline \multirow{4}{*}{$\begin{array}{l}\mathrm{Si}(001), \\
\text { B-doped, } \\
\text { p-type }\end{array}$} & $112.14^{\mathrm{c})}$ & 0.1501 & 6.5328 & 0.00687 & \multirow{4}{*}{$\begin{array}{c}\text { T.F. Page, } 1992, \text { J Mater } \\
\text { Res } 7,450\end{array}$} \\
\hline & 121.75 & 0.2522 & 15.2899 & 0.02687 & \\
\hline & 155.62 & 0.3309 & 25.2002 & 0.1942 & \\
\hline & 160.62 & $0.4917^{\mathrm{a})}$ & up to $50 \mathrm{mN}$ & $0.3014^{\mathrm{b})}$ & \\
\hline \multirow{3}{*}{$\mathrm{Si}(100)$} & 123.2 & 0.4077 & 29.1622 & 0.1545 & \multirow{3}{*}{$\begin{array}{l}\text { S.V. Hainsworth 1996, J } \\
\text { Mater Res 11, } 1987\end{array}$} \\
\hline & 145.44 & 0.7245 & 81.0015 & 0.4684 & \\
\hline & 151.53 & $0.81968^{a)}$ & up to $100 \mathrm{mN}$ & $0.5659^{\mathrm{b})}$ & \\
\hline
\end{tabular}

\footnotetext{
${ }^{\text {a) }} h_{\text {end }}(\mu \mathrm{m}) ;{ }^{\text {b) }}$ final $W_{\text {applied }} / \mathrm{mN} ;{ }^{c)} k_{2}=124.80$ from a separate measurement up to $11 \mathrm{mN}$ after cut-off of the initial effect at $1 \mathrm{mN}$, including the hydrated oxide layer.
} 
Vickers, Brinell, Rockwell, etc. hardness measurements. Interestingly, already microindentations ( $\mathrm{mN}$ to low $\mathrm{N}$-ranges) are a rich but hitherto undetected field of consecutive phase-transitions. Table 3 shows it for the standard materials soda lime glass, aluminium, and silicon, the latter on two different faces (another example is calcite in Table 1$)$. The $h_{\text {end }}$ and $W_{\text {applied }} / \mathrm{mN}$ values indicate only the experimental range. The undoubtedly amorphous soda lime glass exhibits two endothermic phase-transitions at the microindentation range (sharp kinks with linear branches in the Kaupp-plot) and exists thus in 4 or together with the macroindentation 5 polymorphic forms, the structures of which are subject to further studies. We can only conclude from the absence of cracks or pop-ins that there are different degrees of density under load that increases the penetration resistance from state to state. The transition energies of the first two transitions of soda lime glass vary by a factor of roughly 4 , which is quite remarkable. Aluminium requires about 12.1 and $60.4 \mathrm{mN}$ load for its first and second phase-transition and its proper use as a calibration standard ends already below the values of the first one. Some onset-depths are still in a range of nanoindentations. Also the transition work for both transitions is similar to the one of much harder sapphire and smaller than the ones of pinewood (Table 1) and PE, PP, and PS (Table 2). This reflects the weak metallic bonds of aluminium that facilitate rearrangements in the crystal lattice.

The transitions of cubic silicon (Ed3m), exhibiting an exceptional pop-out of the unloading curve, found more theoretical interest. Several polymorphs (including an amorphous phase) were detected by electron diffraction, Raman spectroscopy, and electric conductance onset from the loading curve [10]. The obtained values from the papers, as cited in [10], are similar to the ones found more easily directly from the Kaupp-plot of the loading curve in Table 3. Particularly helpful in that respect are the in-situ current flow onsets at about $5 \mathrm{mN}$ of the metallic Si II [23], which agrees with the first kink discontinuity in our analysis. This electrical unsteadiness confirms again the first phase-transition onset under the (001) face of silicon. We observe however 3 phase-transitions (5 polymorphs) from the physical Kaupp-plots (Table 3). And the data from the two different faces exhibit considerable differences. The first transition is hidden at the scales of 50 and $100 \mathrm{mN}$. It is thus helpful that also a nanoindentation was published in [24] for the (001) face. The variation of the 3 endothermic transition energies is by a factor of 28 for the (001) indention and there were no pop-ins but only "fine cracks emanating from the corners" at $50 \mathrm{mN}$ load/displacement. It can be assumed that the boron-doping does not make much difference to the mechanical properties of silicon. We can, therefore, compare the (001) with the (100) phase. The five polymorphs of the silicon in the loading curve up to $50 \mathrm{mN}$ load have been located for the first time together with the energetic information. The striking differences in the endothermic phase-transition energies at the different faces require a crystallographic understanding. This can be obtained by considering the crystal structure, similar to the procedure, as developed in [16]. Figure 3 compares the different surface structures. It shows the two probed sur- 
faces of silicon. The channels under (001) are slightly smaller than the ones under (100). That explains the deeper onset penetration under (100), but it cannot explain the differences in the corresponding transition onset forces $F_{\mathrm{N}-\text { kink }}$ and the phase-transition energies $W_{\text {transition }}$. We have thus to consider how the Berkovich indenter with its skew faces at the face angle (semi angle $\theta=65.3^{\circ}$ ) interacts orthogonally with the interior of the crystal at the opposite angle, due to the penetrated Berkovich. The equally skew face structures around the Berkovich are calculated by rotations from the indented face by $\mathrm{rx} \pm 65^{\circ}$ and $\mathrm{ry} \pm 65^{\circ}$. This models 8 opposing skew faces because the corresponding rotations around $245^{\circ}$ and $115^{\circ}$ are mirrored or doubly mirrored. Figure 4 and Figure 5 image the striking differences. Figure 4 under (001) exhibits large channels for migrations that facilitate
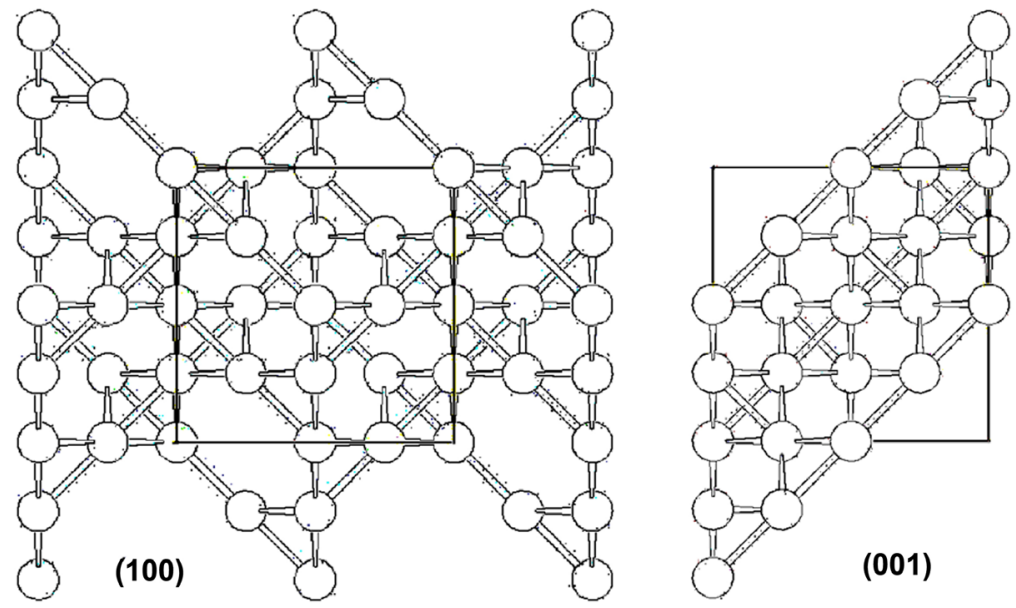

Figure 3. View onto the two indented crystal surface structures of silicon.
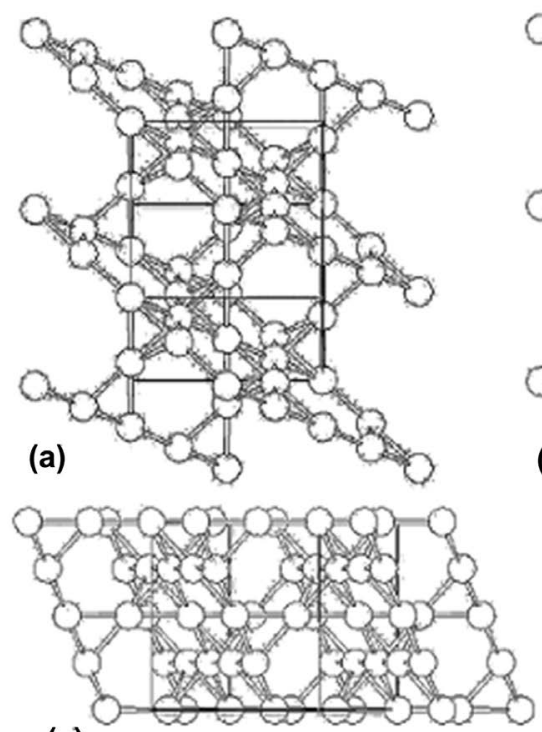

(c)
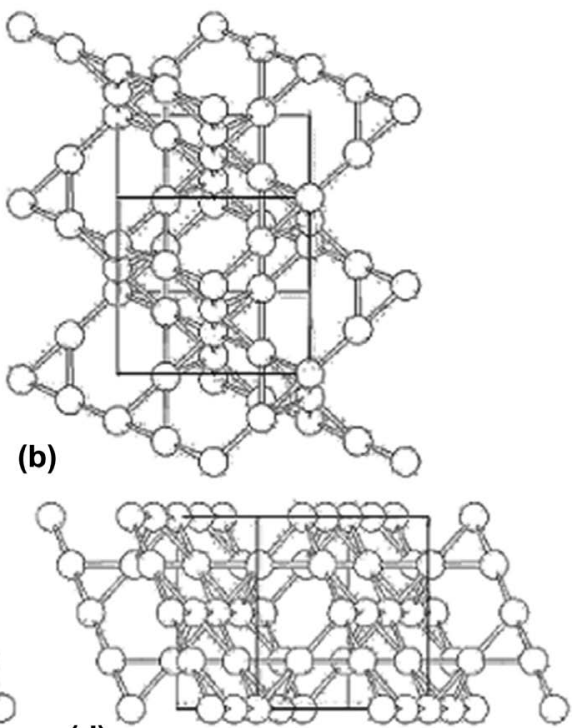

(d)

Figure 4. Silicon skew faces as obtained by the rotations from (001); (a) $r x=65^{\circ}$, (b) $r x=$ $-65^{\circ}$, (c) ry $=65^{\circ}$, (d) ry $=-65^{\circ}$. 


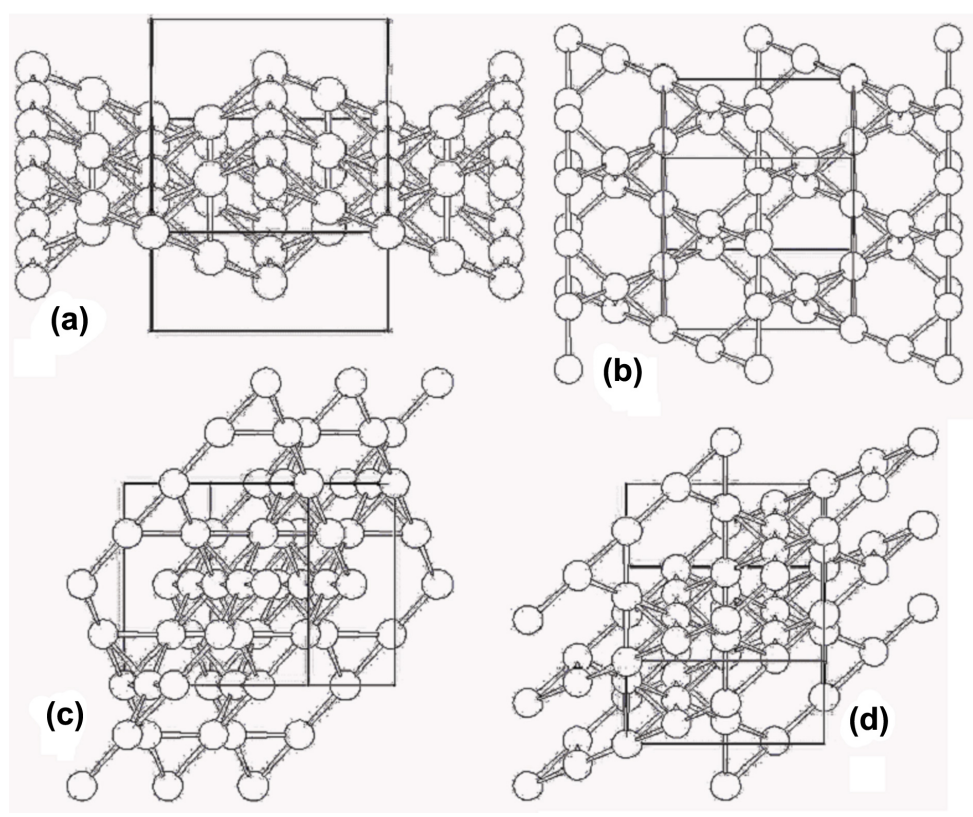

Figure 5. Silicon skew faces as obtained by the rotations from (100); (a) $r x=65^{\circ}$, (b) $r x=$ $-65^{\circ}$, (c) ry $=65^{\circ}$, (d) ry $=-65^{\circ}$.

the phase changes. Clearly, that makes them less endothermic. Conversely, in the correspondingly calculated Figure 5, under (100) one observes 3 blocking (a, c, d) opposing faces and only one (b) with channels. Clearly, the migrational possibilities are more impeding under (100). The phase-transition and the endothermic result are thus considerably higher, as has to be expected.

\subsection{Further Face-Dependent Phase-Transitions}

The multiple phase transitions of silicon (Berkovich) are also face specific and this is described in detail in Section 3.3, Table 3 and Figures 3-5. Also, the anisotropic single exothermic phase-transition energies of $\alpha$-quartz (cube corner) on four different faces have already been analyzed for crystallographic reasons and reported in [16]. All crystalline materials must have different phase-transition energies under different faces. Further typical examples are with bcc $\alpha$-iron (ferrite, $\operatorname{Im} 3 \mathrm{~m})$ under two faces and with strontium titanate perovskite type $(\mathrm{Pm}-3 \mathrm{~m})$ under three faces (Table 4). These measurements require the high precision that is only available with the physical regression analysis without iterations or data fittings.

The crystal of $\alpha$-iron on (100) and (110) exhibits different exothermic phase-transition values. For strontium titanate with three endothermic phase-transition energies, two of them have closer together values, but the lowest and largest values are far apart. This is again not consistently reflected by the different onset forces and onset depths (Table 4). The reasons are the different crystal packing, similar to the reasoning with silicon (Table 3) and $\alpha$-quartz in [16]. The understanding of the exothermic phase-transition of $\alpha$-iron rests again on the fact that the penetrating pyramid interacts orthogonally with its opposing 
Table 4. Face-dependent phase-transition onsets and transition energies of $\alpha$-iron and strontiumtitanate.

\begin{tabular}{ccccccc}
\hline Material & $\begin{array}{c}k_{1} \text { and } k_{2} \\
\mu \mathrm{N} / \mathrm{nm}^{3 / 2}\end{array}$ & Indenter & $\begin{array}{c}h_{\text {kink }} \\
\mathrm{nm}\end{array}$ & $\begin{array}{c}F_{\mathrm{N}-\text { kink }} \\
\mu \mathrm{N}\end{array}$ & $\begin{array}{c}W_{\text {transition }} \\
\mu \mathrm{Nnm} / \mu \mathrm{N}\end{array}$ & Data Origin \\
\hline $\mathrm{Fe}(100)$ & $\begin{array}{c}0.3590 \\
0.2618\end{array}$ & Cube Corner & 103.0337 & 461.9156 & -40.0372 & $\begin{array}{c}\text { Smith, Phys Rev } \\
\text { B2003, 67 245405 }\end{array}$ \\
& $\begin{array}{l}0.2332 \\
\mathrm{Fe}(110)\end{array}$ & Cube Corner & 109.0949 & 358.9707 & -33.5112 & ditto \\
& 0.1986 & & & & & Kaupp, Scanning \\
$\mathrm{SrTiO}_{3}(100)$ & 3.0436 & Berkovich & 69.7824 & 1738.2160 & 6.489 & $2013,35,392$ \\
& 3.7145 & & & & & ditto \\
$\mathrm{SrTiO}_{3}(110)$ & $\begin{array}{l}2.5217 \\
3.3841\end{array}$ & Berkovich & 65.7308 & 1355.4438 & 7.020 & ditto \\
$\mathrm{SrTiO}_{3}$ & 2.7591 & & & & & \\
$(111)$ & 4.0878 & Berkovich & 102.8636 & 2860.4600 & 14.821 & \\
\hline
\end{tabular}

skew face at the semi-angle, which is $\theta=35.26^{\circ}$ for the cube corner. A rotation from the surface faces around $x$ and $y$ by $\pm 35^{\circ}$ yield these skew surfaces. The eight by $35^{\circ}$ inclined faces around the three-sided indenter pyramid are completely represented with only two images for symmetry reasons of the bcc cubic crystal under (100) (Figure 6) and under (110) (Figure 7). This facilitates the understanding of the differences for crystallographic reasons.

The crystal face on (100) and the skew faces under it in Figure 6 under (100) stand for the higher exothermic phase-transition of $\alpha$-iron. The cube corner opposes all of the eight faces almost orthogonally that are devoid of channels. That means, there is no energy lost by the migration of phase transformed material. The gained exothermic energy remains highly negative.

Conversely, Figure 7 with Fe on (110) with the lower exothermic phase-transition energy shows the skew faces by rotations of $\pm 35^{\circ}$ from it. Four of the eight exhibit open channels orthogonally to the indenter. Therefore, part of the gained transition-energy is used up for migration of the phase transformed material, leaving less of the gained energy by phase-transition. The channel face is here fortuitously the $\{111\}$ faces across the crystal. Only the other four faces impede migrations.

The analogous analysis has been successful with the exothermic phase-transition of $\alpha-\mathrm{SiO}_{2}$ with cube corner in [16], where 4 different faces were studied: the absence of channels retains exothermic negative transition energy. Everything is thus well understood by the straightforward analysis in the case of exothermic phase-transition.

As already shown for the endothermic phase-transitions of silicon in Section 3.3, the analysis of the strontiumtitanate using Berkovich with $\theta=65.3^{\circ}$ is equally successful (not imaged here, due to many images that are required). The minimal endothermic work $(6.5 \mu \mathrm{Nnm} / \mu \mathrm{N})$ is required under (100), where channels are available on the skew faces to facilitate the conversion. Conversely, under (111) the strongest endothermic energy $(14.8 \mu \mathrm{Nnm} / \mu \mathrm{N})$ is observed, as there are no channels at the skew faces that enforce the transition to stay blocked 


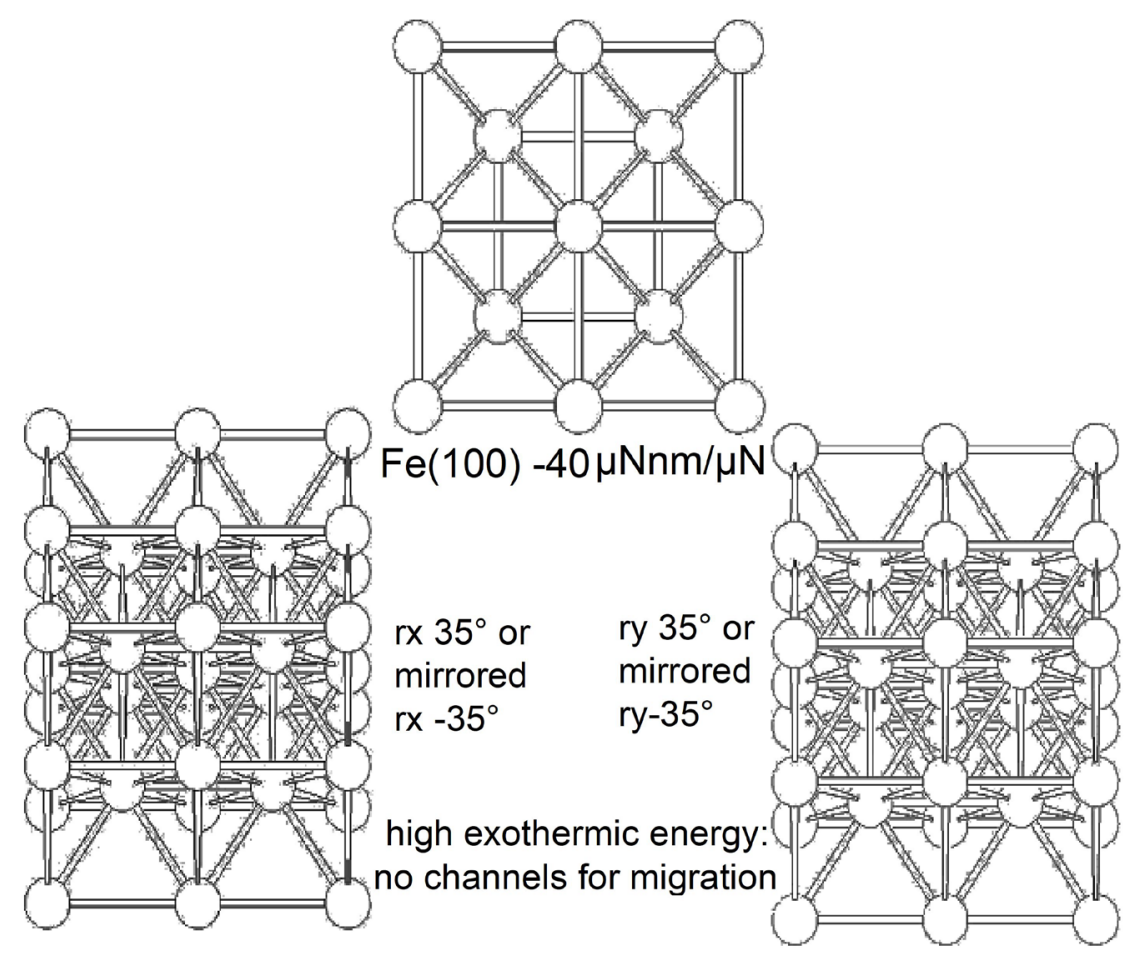

(the other 4 rotation possibilities repeat these by symmetry)

Figure 6. The $\alpha$-iron (100) face and those as obtained by rotations from it by $\mathrm{rx}=35^{\circ}$ and ry $=35^{\circ}$, modelling all eight skew surfaces that surround the penetrated cube corner indenter for symmetry reasons, leaving no channels for migrations.

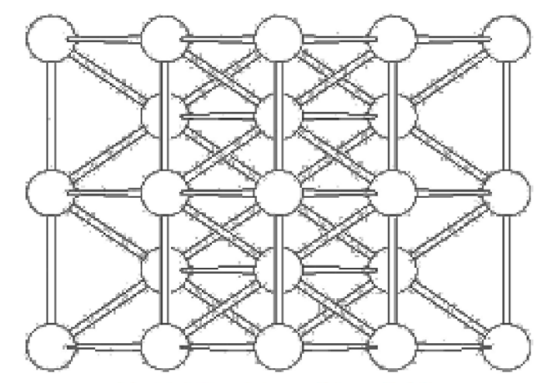

$\mathrm{Fe}(110)-33.5 \mu \mathrm{Nnm} / \mu \mathrm{N}$

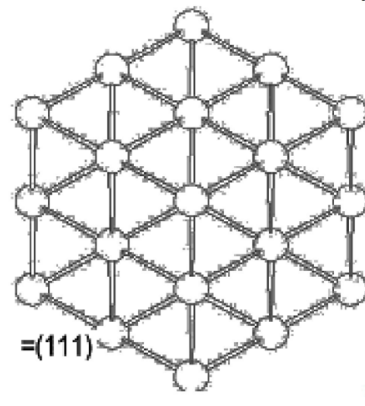

$r \times 35^{\circ}$ or mirrored $\mathrm{rx}-35^{\circ}$

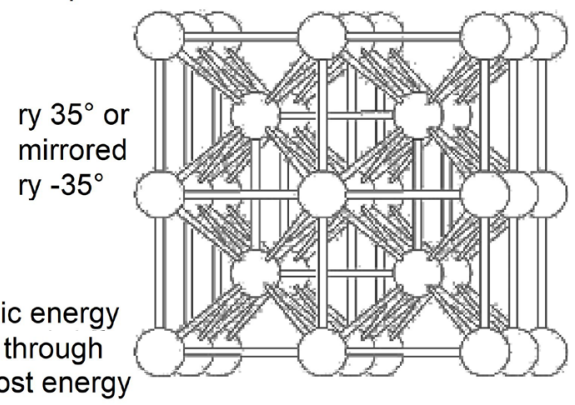

(the other 4 rotation possibilities repeat these by symmetry)

Figure 7. The $\alpha$-iron (110) face and those as obtained by rotations from it by rx $=35^{\circ}$ and ry $=35^{\circ}$, modelling by symmetry all eight skew surfaces that almost orthogonally surround the penetrated cube corner indenter, four of them (here fortuitously $\{111\}$ ) with open channels for migrations. 
in space, which increases the endothermic work. Consistently, under (110) the value $(7.0 \mu \mathrm{Nnm} / \mu \mathrm{N})$ stays between the extremes, as there are some smaller channels allowing for minor migration of the transformed material. Again, channels facilitate migrations for the endothermic phase-transitions and decrease the endothermic work. When migrations are blocked more work is required for the phase-transition. The face-dependency of phase-transition energies is thus well understood by crystal structure analysis.

\subsection{Phase-Transition Energies of Superalloys}

The sudden first order sharp phase-transitions form polymorph interfaces that are shifted away from the indenter after their onset when the load increases. These polymorph interfaces are preferential sites for the nucleation of large far-distant cracks. This has already been imaged in connection with the multiple consecutive phase-transitions of sodium chloride in [17]. These circumstances are most important for the occurrence of catastrophic failures of superalloys at work. Clearly, polymorph interfaces must be avoided with materials under mechanical and thermal stress. We must therefore urgently look for phase-transition onsets and transition energies of published loading curves of some superalloys (also called entropic alloys). This shall convince industries that they must complement their Vickers, Brinell, Rockwell, etc. hardness measurements with physical depth-sensing macroindentations' control. Only these provide the necessary phase-transition information. The problems might occur primarily after multi-1000-fold load and unload both mechanically and thermally. The thermal stress calculation requires the activation energy of the phase-transitions that can also be obtained by physically correct temperature dependent indentations [10]. The transition energies $W_{\text {trans }}$ in Table 5 are purposely given in $\mu \mathrm{Nnm} / \mu \mathrm{N}$ units, in order to show that such phase transformations can also here occur at comparatively low loads and depths. There were no "pop-ins", which could disqualify

Table 5. Unprecedented phase-transition qualities of $\gamma$-TiAl and various superalloys.

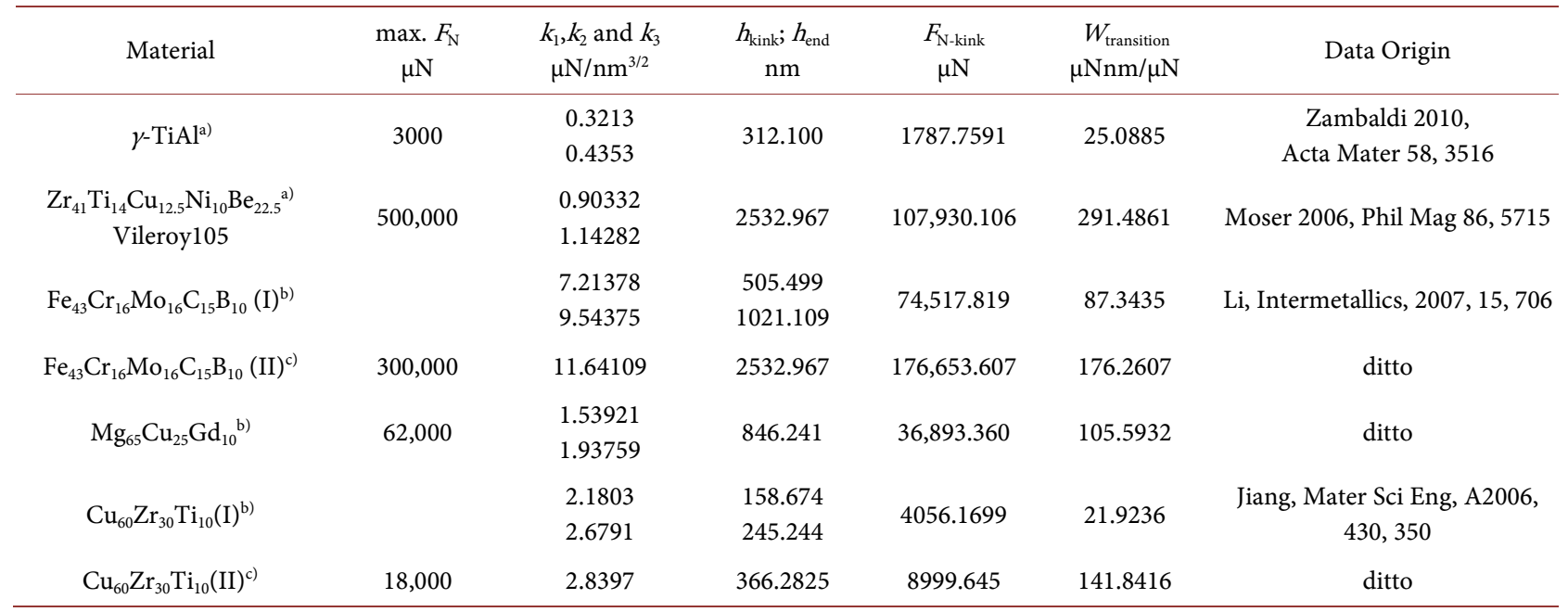

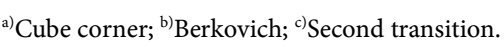


the alloy's use beforehand. However, these published examples do certainly not represent alloys that are in practical use, as the actual alloys are secret and only available to the industrial personnel.

Table 5 starts with the 68/32 $\gamma \mathrm{TiAl}$ alloy, because a propeller blade close to the turbine each out of a "titanium-aluminium alloy" from two identical airliners broke away, during flight within one year in 2017 and 2018. Both blades hit the body of the airliners, unfortunately killing a woman passenger. This "titanium aluminium alloy" of publicly unknown composition contained certainly several other components. The data of Table 5 show however comparably low force and energy values for the phase-transition of the alloy base TiAl. It is seen: the way for obtaining high enough phase-transition onset and endothermic transition energy for a reasonable TiAl alloy must probably have been too long. The other alloys of Table 5 exhibit much higher values, but these alloys are certainly not the secret alloys for airplanes. There are means to engineer alloys by trial and error with ductilizers, for example by oxide dispersion strengthening (ODS-superalloys) with $\mathrm{Y}_{2} \mathrm{O}_{3}, \mathrm{ThO}_{2}, \mathrm{La}_{2} \mathrm{O}_{3}, \mathrm{Al}_{2} \mathrm{O}_{3}$, etc. [25]. Also, carbon and other materials have been widely used as additives. Here is now the still not industrially used (legal ISO-ASTM standard certification!) more systematic way to improve superalloy compositions for best performance. All what's required is the easy and reliable physical indentation analysis with respect to phase-transitions. The hardness of materials is again a poor guide for judging the phase-transition onset force ranges and the phase-transition energies. For example, the by far best alloy in Table 5 is Vileroy-105 with a comparably low hardness $\left(k_{1}=0.90332\right.$ $\mu \mathrm{N} / \mathrm{nm}^{3 / 2}$ or with other units $29.652 \mathrm{mN} / \mu \mathrm{m}^{3 / 2}$ ) that are much smaller than those of $\mathrm{Fe}_{43} \mathrm{Cr}_{16} \mathrm{Mg}_{16} \mathrm{C}_{15} \mathrm{~B}_{10}\left(k_{1}=7.21378 \mu \mathrm{N} / \mathrm{nm}^{3 / 2}\right.$ or with other units $\left.228.12 \mathrm{mN} / \mu \mathrm{m}^{3 / 2}\right)$, while the $W_{\text {transition }}$ ratio is $291 / 87$, respectively. The Newton-range is almost reached with Vileroy-105. Its first transition is at highest force and also the transition energy is highest, whereas the well-known iron-based superalloy surmounts the kink force only at its second phase-transition but with much lower transition energy. The magnesium based alloy is inferior and the copper-based alloy has two phase-transitions at still lower forces and transition energies.

The here achieved maximal loading forces $(0.5 \mathrm{~N}$, corresponding to HV 0.05$)$ are at or below the lower level of industrial Vickers, Brinell, Rockwell, etc. hardness measurements. These are certainly highly standardized by ASTM, but unable to detect phase-transitions. It is to be expected that further as yet undetected phase-transitions will occur at the much higher loads (for example from Vickers hardness HV 0.5 to HV 10) in all cases.

The field of superalloys for technical constructions is widespread and extremely important, and so is the improvement of the stability of superalloys when being at work. Any alloy must only be admitted to forces below its first phase-transition onset. Both the onset force and the transition energies must be as high as possible. We present here a simple systematic way to improve the engineers' efficiency, but this depends on the profound change of the present ISO 
and ASTM standards that are the basis of the manufacturer's certification. Physical mathematically proved standards must be urgently created, edited, and enforced. Present ISO-ASTM hardness or indentation moduli are not physical quantities and they are unsuitable for the safety. Their biggest flaw is their inability to detect or even know of phase-transitions under load. The here described improvements are, of course, worldwide indispensable, but unfortunately not easily achieved for various unscientific reasons.

\section{Conclusion}

We showed here that undeniable sacrosanct basic calculation rules prove the physically founded Equation (1) [7] for pyramidal (or conical) indentations. These lead to the detection and energetic characterization by calculations with proof of the universal evaluation formulas. Phase-transition onset and phase-transition energies have been calculated across all material types. These include multiple transformations and surface dependent ones at various load conditions. Special effects are detected and corrected because bulk qualities are aimed at. Instrument builders are urged to offer the corresponding software for automatic calculation of these quantities. It is impossible to judge the ranges of phase-transition onset forces and energies from hardness and elastic moduli that violate the energy law [11] [18] [19]. The wrong exponent 2 on $h$ and the violation of the energy law are intolerably incomprehensible and must be pitiless rejected. The whole world should no longer be forced to assume that the elastic pressure deformation plus all of the pressure induced plastic deformations can be obtained from nothing. The presented measurements indicate again that phase-transitions of materials under mechanical or thermal stress facilitate catastrophic breakages [17]. ISO and ASTM must thus normatively require the detection of the onset and transition energies for all technically used materials. And for safety reasons, admission of all materials must be restricted to forces (temperatures) well below their first phase-transition. For thermal stress, the activation energy of the first phase-transition [10] must be calculated and its constancy after the long running routines equally secured. The ISO 14577 standard must urgently be changed. In the meantime, Certification Agencies must stop using ISO 14577 for the certification procedure of industrial companies. Only that stopping will enable them to perform the required use of the calculation rules with depth sensing (macro) indentations for the search of phase-transition onsets and energies. This is, of course, additionally required after the standard stretching and bending tests for all materials. It will also be necessary upon the legally prescribed maintenance routines and particularly for a posteriori tests after the recent catastrophic events of e.g. broken off propeller blades in front of turbines, etc. It will clarify the reasons and avoid further risks with replaced materials for safety reasons. This paper shall help in that endeavor. Future research must also routinely include reliable low and very low-temperature indentations of technical materials to search for embrittlements (no pop-ins allowed) and additional low-temperature phase-transitions. 
First examples at $-63^{\circ} \mathrm{C}$ [26] and $-113^{\circ} \mathrm{C}$ [27] are already available, but the proved mathematical analyses were not used. We try cooperation at an applied instrument with such capabilities and continue with worldwide lecturing on this important subject.

\section{Conflicts of Interest}

The authors declare no conflicts of interest regarding the publication of this paper.

\section{References}

[1] Kaupp, G. and Naimi-Jamal, M.R. (2013) Penetration Resistance and Penetrability in Pyramidal (Nano)Indentations. Scanning, 35, 88-111.

https://doi.org/10.1002/sca.21038

[2] Love, A.E.H. (1939) Boussinesq's Problem for a Rigid Cone. The Quarterly Journal of Mathematics (Oxford), 10, 161-175. https://doi.org/10.1093/qmath/os-10.1.161

[3] Sneddon, I.N. (1965) The Relation between Load and Penetration in the Axisymmetric Boussinesq Problem for a Punch of Arbitrary Profile. International Journal of Engineering Science, 3, 47-57. https://doi.org/10.1016/0020-7225(65)90019-4

[4] Oliver, W.C. and Pharr, G.M. (1992) An Improved Technique for Determining Hardness and Elastic Modulus Using Load and Displacement Sensing Indentation Experiments. Journal of Materials Research, 7, 1564-1583.

https://doi.org/10.1557/JMR.1992.1564

[5] Kaupp, G. and Naimi-Jamal, M.R. (2004) Nanoscratching on Surfaces: The Relationships between Lateral Force, Normal Force and Normal Displacement. International Journal of Materials Research, 95, 297-305. https://doi.org/10.3139/146.017952

[6] Naimi-Jamal, M.R. and Kaupp, G. (2005) Quantitative Evaluation of Nanoindents: Do We Need More Reliable Mechanical Parameters for the Characterization of Materials? International Journal of Materials Research, 96, 1226-1236. https://doi.org/10.3139/146.101166

[7] Kaupp, G. (2016) The Physical Foundation of $F_{\mathrm{N}}=k h^{3 / 2}$ for Conical/Pyramidal Indentation Loading Curves. Scanning, 38, 177-179. https://doi.org/10.1002/sca.21223

[8] Kaupp, G. (2013) Penetration Resistance: A New Approach to the Energetics of Indentations. Scanning, 35, 392-401. https://doi.org/10.1002/sca.21080

[9] Merle, B., Maier, V. and Durst, K. (2014) Experimental and Theoretical Confirmation of the Scaling Exponent 2 in Pyramidal Load Displacement Data for Depth Sensing Indentation. Scanning, 36, 526-529. https://doi.org/10.1002/sca.21151

[10] Kaupp, G. (2014) Activation Energy of the Low-Load NaCl Transition from Nanoindentation Loading Curves. Scanning, 36, 582-589. https://doi.org/10.1002/sca.21158

[11] Kaupp, G. (2017) The ISO Standard 14577 for Mechanics Violates the First Energy Law and Denies Physical Dimensions. Journal of Material Sciences and Engineering, 6, 321-328. https://doi.org/10.4172/2169-0022.1000321

[12] Zeng, K. and Chiu, C.H. (2001) An Analysis of Load-Penetration Curves from Instrumented Indentation. Acta Materialia, 49, 3539-3551. https://doi.org/10.1016/S1359-6454(01)00245-2

[13] Hainsworth, S.V., Chandler, H.W. and Page, T.F. (1996) Analysis of Nanoindenta- 
tion Load-Displacement Curves. Journal of Materials Research, 11, 1987-1995. https://doi.org/10.1557/JMR.1996.0250

[14] Troyon, M., Abbes, F. and Garcia Guzman, J.A. (2012) Is the Exponent 3/2 Justified in Analysis of Loading Curve of Pyramidal Nanoindentations? Scanning, 34, 410-417. https://doi.org/10.1002/sca.21025

[15] Soare, S., Bull, S.J., Oila, A., O’Neill, A.G., Wright, N.G. Horsfall, A. and dos Santos, J.M.M. (2005) Obtaining Mechanical Parameters for Metallization Stress Sensor Design Using Nanoindentation. International Journal of Materials Research, 96, 1262-1266. https://doi.org/10.3139/146.101172

[16] Kaupp, G. (2019) Phase-Transition Energies, New Characterization of Solid Materials and Anisotropy. Advances in Materials Physics and Chemistry, 9, 57-70. https://doi.org/10.4236/ampc.2019.94006

[17] Kaupp, G. (2018) Six Polymorphs of Sodium Chloride upon Depth-Sensing Scanning Macroindentatiom with Unusual Long-Range Cracks Requiring $30 \mathrm{~N} \mathrm{Load.}$ Journal of Material Sciences and Engineering, 7, 473-483. https://doi.org/10.4172/2169-0022.1000473

[18] Kaupp, G. (2017) Dilemma between Physics and ISO Elastic Indentation Modulus. Journal of Material Sciences and Engineering, 6, 402-405.

[19] Kaupp, G. (2017) Challenge of Industrial High-Load One-Point Hardness and of Depth Sensing Modulus. Journal of Material Sciences and Engineering, 6, 348-355. https://doi.org/10.4172/2169-0022.1000348

[20] Keller, E. (1997) Schakal 97. Kristallographisches Institut der Universität Freiburg i. Br., Germany.

[21] Lin, J.F., Degtyareva, O., Prewitt, C., Dera, P., Sata, N., Gregoryanz, E., Mao, H.K. and Hemley, R.J. (2004) Crystal Structure of a High-Pressure/High-Temperature Phase of Alumina by In-Situ X-Ray Diffraction. Nature Minerals, 3, 389-393. https://doi.org/10.1038/nmat1121

[22] Thurn, J., Morris, D.J. and Cook, R.F. (2002) Depth-Sensing Indentation at Macroscopic Dimensions. Journal of Materials Research, 17, 2679-2690. https://doi.org/10.1557/JMR.2002.0388

[23] Bradby, J.E., Williams, J.S. and Swain, M.V. (2003) In Situ Electrical Characterization of Phase Transformations in Si during Indentation. Physical Review B, 67, Article ID: 085205. https://doi.org/10.1103/PhysRevB.67.085205

[24] Page, T.F., Oliver, W.C. and McHargue, C.J. (1992) The Deformation Behavior of Ceramic Crystals Subjected to Very Low Load (Nano)Indentations. Journal of Materials Research, 7, 450-473. https://doi.org/10.1557/JMR.1992.0450

[25] Kaupp, G. (2011) Reactive Milling with Metals for Environmentally Benign Sustainable Production. CrystEngComm, 13, 3108-3121. https://doi.org/10.1039/c1ce05085k

[26] Wang, S., Liu, H., Xu, L., Du, X., Zhao, D., Zhu, B., Yu, M. and Zhao, H. (2017) Investigation of Phase Transformation in Monocrystalline Silicone at Low Temperatures via Nanoindentation. Scientific Reports, 7, Article No. 8682. https://doi.org/10.1038/s41598-017-09411-x

[27] Lee, S.W., Meza, L. and Greer, J.R. (2013) Cryogenic Nanoindentation Size Effect in $\left[\begin{array}{lll}0 & 0 & 1\end{array}\right]$-Oriented Face-Centered Cubic and Body-Centered Cubic Single Crystals. Applied Physics Letters, 103, Article ID: 101906. https://doi.org/10.1063/1.4820585 